University of Nebraska - Lincoln

DigitalCommons@University of Nebraska - Lincoln

2009

\title{
The Child Outcomes of a Behavior Model
}

\author{
J. Ron Nelson \\ University of Nebraska - Lincoln, rnelson8@unl.edu \\ Kristin Duppong-Hurley \\ University of Nebraska-Lincoln, kristin.hurley@unl.edu \\ Lori Synhorst \\ University of Nebraska - Lincoln, Isynhorst2@unl.edu \\ Michael Epstein \\ University of Nebraska - Lincoln, mepstein1@unl.edu \\ Scott Stage \\ North Carolina State University, scott_stage@ncsu.edu \\ See next page for additional authors
}

Follow this and additional works at: https://digitalcommons.unl.edu/specedfacpub

Part of the Special Education and Teaching Commons

Nelson, J. Ron; Duppong-Hurley, Kristin; Synhorst, Lori; Epstein, Michael; Stage, Scott; and Buckley, Jacquelyn, "The Child Outcomes of a Behavior Model" (2009). Special Education and Communication Disorders Faculty Publications. 57.

https://digitalcommons.unl.edu/specedfacpub/57

This Article is brought to you for free and open access by the Department of Special Education and Communication Disorders at DigitalCommons@University of Nebraska - Lincoln. It has been accepted for inclusion in Special Education and Communication Disorders Faculty Publications by an authorized administrator of DigitalCommons@University of Nebraska - Lincoln. 


\section{Authors}

J. Ron Nelson, Kristin Duppong-Hurley, Lori Synhorst, Michael Epstein, Scott Stage, and Jacquelyn Buckley 


\title{
The Child Outcomes of a Behavior Model
}

\author{
J. RON NELSON \\ KRISTIN DUPPONG HURLEY \\ LORI SYNHORST \\ MICHAEL H. EPSTEIN \\ Thirersity of Nobrakid. Limin \\ SCOTT STAGE \\ North Garolina litate insterstoy \\ JACQUELYN BUCKLEY \\ Jaims Hopkins innersity
}

Aвsтract: Within 3-tier behavioral models, wineral intenentions are expected to prevent the onset of problem behavior in a majority of children altogether and to sustain improvements in child outcomes by the selected and indicated interventions. A cohort longitudinal design uas wsed to assess the extent to which a 3-tier model achieves these expected outcomes. The respective universal, selected, and indicated interventions included Behavior and Academic Support and Enhancement. First Step to Success, and MultiSystemic Therapy. A total of 407 children in Grades K-3 from $I$ of 4 longitudinal coborts participated. The results of 2-level linear grouth analyses indicate that the 3-tier behation model achieved the anticipated outcomes with respect to social behavior. The results, limitations, and implications are discussed.

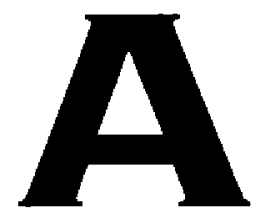

$n$ estimated $! 2 \%$ of all children and adolescents in this country have significanc emorional and/or behavioral disorders (EBD) that adversely affect rheir social functioning (Department of Health and Human Services, 2000: Pulosi, 1996). Schools rypically implement a wide range of isolated incerventions ( $\epsilon . \mathrm{g}$. group and individual contingency programs, self-management, sncial skills instruction) to address the emotional and social needs of these children (Beelman, Pfingsten, \& Losel. 1994: Zins, Weissberg, Wang, \&
Walberg, 2004). Zins and colleagues reported that schools, on average, implement 14 interventions to ameliorate the behavioral challenges of children wirh or at risk of EBD. Scholars and others have recommended that schools use rhrectier behavior models as an alternative to the in\}plementation of isolated interventions (c.g.. Gresham, 2004; Horner, Sugai, Todd, \& lewisPalmer, 2005; Sugai, 2007). Such models are an attractive prevention-oriented alternative to the approach of trying a wide range of isolated interventions ro ancliorate the behavioral challenge of children with or ar risk of EBD. 
Within the public and behavioral health fields, three-tier behavior models are conceptualized differently (Mrazek \& Haggetty, 1994). In the public bealth field the three tiers are categorized as primary, secondary, and tertiary. Primary prevention is direcred at preventing a potential problem; secondary prevention is directed at early derecrion and intervention to delay onset or mitigate a problem, and tertiary prevention is directed at minimizing disability añd avoiding relapse of a problem. In addition, the rhree-tiet behavior model from the public health field is often used within a response-to-intervention framework, which involves moving ro more intensive levels of treatment when the interventions from the less intensive tier do not produce the desired outcomes (e.g., Gresham, 2004; Horner er al., 2005; Sugai, 2007). Thus, in almost all cases, a student would not be assigned to nor experience a tertiary intervention until afrer a secondary intervention had been applied and determined not to work.

In the bebavioral bealth field, three-tier behavior models are correlated directly with levels of risks in target populations (Mrazek \& Haggerry, 1994). The three tiers in the behavioral health field are categorized as universal, selected, and indicared. This classification of tiers is based on a classification system proposed more than a decade carlier (Gordon, 1983). Universal interventions are directed at the general population. Selected intervenrions are directed at targeted groups at greater risk than the rest of the population. Indicated interventions are directed only to high-risk individuals and those who are experiencing a disorder to reduce its severity and/or duration. The three-tier behavior model from the behavioral health field uses information on degree of risk to identify the appropriate intensity of intervention for the general, at-risk, and highrisk/disordered populations. The degree of risk data may be indicated by demographic factors, family functioning, past and current levels of behavioral and academic funcrioning, and orher relevant risk variables. Thus, in almost all cases, a student is immediately assigned to and experiences a selected or indicated intervention based on his or her degree of risk. In addition, it is important to note that students who receive the selected and indicated interventions also receive the universal intervention that it is delivered to all students.

Although the public and behavioral health models are both focused on prevention and are effective for systematically organizing and implementing ricrs of interventions, the behavioral health model aligns more directly with the universal, selected, and indicated interventions we used to operationalize our three-tier behavioral model. Each tier of intervention was designed to intervene with varying degrees of risk for EBD. The respective universal, selected, and indicared interventions include: (a) Behavior and Academic Support and Enhancement (BASE; Nelson, 1996; Nelson, Martella, \& Marchand-Martella, 2002); (b) First Srep to Success (Walker et al, 1997); and (c) MulciSystemic Therapy (MST; Henggeler, Schoenwald, Borduin, Rowland, \& Cunningham, 1998). These interventions were selected based on three criteria. First, the incerventions had to represent greater specificity in the rype of problem rargeted. comprehensiveness, and incensity. Second, the interventions had to be standardized to ensure that they could be replicated reliably. Finally, the interventions had to be fully developed and validated through applied rescarch studies.

\section{In the behavioral health field, three-tier behavior models are correlated directly with levels of risks in target populations.}

Three-tier behavioral models such as the one studied here are expected to achieve a range of important child outcomes in relationship to the universal, selected, and indicated incerventions (Mrazek \& Haggerty, 1994). Universal interventions are expected to prevent the development of problem behavior in a majority of children altogether and to sustain reductions in problem behavior achieved by the selected and indicated interventions. Selected interventions are assumed to prevent the onset of problem behavior by children at risk of behavior problems through the application of interventions early enough to be 
effecrive. Indicated interventions are expected to decrease the severity and/or duration of problem behavior of children with or at high risk of EBD. We implemented a three-tier behavior model based on a behavioral health framework, which as stated, attempts to match an individual child's level of risk with an appropriace level of intervention (i.e., universal, selected, indicated) without having to move through each tier.

This study assessed the extent to which a three-tier behavior model based on a behavioral health framework achieves these expected child ourcomes. Three groups of children were followed over 3 years: (a) Universal (low-risk comparison group), (b) Selected (at-risk) intervention group, and (c) Indicated (high-risk/EBD identified) intervention group. Our primary hyporhesis was that the children in the Universal group would not experience significant changes in theit social behavior (i.e., increases in social skills, decreases in problem behavior) because they were not assigned to Selected or Indicated intervention groups; whereas, children in the Selected and Indicated intervention groups would show improvements in their social behavior relarive to those in the Universal group. We made no comparative hypothesis regarding relative improvements in the social behavior of children in the Selected and Indicated intervention groups because the children receiving these interventions represent fundamentally different popularions of students (at-risk ws. high risk). In addition, given that there is evidence that there is a link between problem behavior and academic performance (Al Otaiba \& Fuchs, 2002, 2006; Lassen, Steele, \& Sailor, 2006; Nelson, Benner, \& Gonzalez, 2003; Nelson, Benner, Lane, \& Smith, 2004), our secondary exploratory hyporhesis was that improvements in the social behavior of childten in the Selected and Indicated intervention groups would be accompanied by positive changes in their academic competence and word reading skills. This hypothesis was considered exploratory because the specific causal mechanisms underlying the relarionship between social behavior and literacy remain unclear (Hinshaw, 1992; Nelson, Srage, Epstein, \& Pietce, 2005).

\section{METHODS}

\section{PARTICIPANTS}

A toral of 407 children (130 girls, 277 boys) in Grades $K$ to 3 from one of four longitudinal cohorts participated: Cohort $1(n=153)$, Cohort 2 $(n=93)$, Cohort $3(n=95)$, and Cohore $4(n=$ 66). The cohorts were selected across four consecurive school years from seven elementary schools located in a medium-size ciry in the midwest. Parental informed consent was obtained in all cases. Our approved Institutional Review Board procedures did not require that we obrain child assent. The average number of children served by the seven schools was 392 (range $=356$ to 471 ). The average percentage of children of color and those eligible for free or reduced lunch were $35 \%$ (range $=10 \%$ to $64 \%$ ) and $61 \%$ (range $=33 \%$ to $86 \%$ ), respectively. The average mobility rate of the schools was $21 \%$ (range $=7 \%$ to $37 \%$ ). The same core academic content programs were used across the participating schools. The average third grade National Normal Curve Equivalent (NCE) scores on the Metropolitan Achievement Test (8th ed.; Pearson Assessment, 2000) in reading and mathematics in the 2005 academic year were 57.0 (range $=50.3$ to 67.1 ) and 60.1 (range $=51.0$ to 73.0), respectively.

Each cohort of participants was comprised of three groups of children: Universal, Selected intervention group, and Indicated intervention group. Children in the Universal and Selected groups were initially enrolled in $\mathrm{K}$ to 1 ; whereas, those in the Indicated intervention group were initially enrolled in $\mathrm{K}$ to 3. A parallel two-step universal screening process was used to identify participants for the Universal and Selected groups. The screening process for kindergarten and first-grade participants included the first and second gates of the Early Screening Project (ESP; Walker, Severson, \& Feil, 1995) and Systematic Screening System for Behavior Disorders (SSBD; Walker \& Severson, 1990), respectively. Step 3 of the ESP and SSBD was nor included because of the significant time and resources required to commit to classroom and playground observarions of student behavior, and the reliability of Steps 1 and 2 in identifying children at risk of EBD (H. M. Walker, personal communication, August, 15, 2002). 
The screening procedure was conducted at the parricipating schools during the fifth or sixth week of the school year for 4 successive years. At Step 1, kindergarten and first grade teachers were provided with a definition and examples of externalizing and internalizing behavioral characteristics arciculared in the ESP and SSBD. Teachers then generated two mutually exclusive lists of children. The first lisc included those children whose characteristic behavior pattern most closely resembled the externalizing behavior description. Teachers then rank ordered these children according to the degree to which their behavior matched the externalizing definition. To generate the second list, an identical procedure was followed to list and rank order children according to the internalizing behavior definition.

At Step 2, kindergarten and first grade reachers completed the three ESP and SSBD scales, respectively (i.e., Critical Events Index, Maladaptive Behavior, Adaptive Behavior) on the five highest externalizing and internalizing children identified in Step 1. (Note that the ESP and SSBD specify that teachers complete Step 2 for only the three highest ranked externalizing and internalizing children. However, to generate a large enough sample of children for the Universal group, ratings were completed on the five highest ranked children.) The ESP and SSBD Critical Events Index has 16 and 33 items, respectively, (e.g., steals, sets fires) that teachers rank as occurring or not occurring. The ESP and SSBD Adaptive Behavior scale includes 8 and 12 items, respectively, that assess teacher- and peer-relared adaptive behavior that teachers rate on a 5-point Likerc rype scale. The ESP and SSBD Maladaptive Behavior scale includes 9 and 11 items, respectively, that assess reacher-and peer-related problem behavior that reachers rate on a 5-point Likert type scale. Teachers' ratings on the ESP and SSBD Adaptive Behavior and Maladaptive Behavior scales are based on the frequency of children's behavior within the past 30 days. The reported test-retest reliabilicies for the ESP (Walker et al., 1995) and SSBD (Walker \& Severson, 1990) Critical Events, Adaptive Behavior, and Maladaptive Behavior scales have demonstrated adequate psychomerric characteristics. The Cronbach's Alphas for the ESP Critical
Events, Adaptive Behavior, and Maladaptive Behavior scales for the study sample were .61, 90, and .87, respecrively. The Cronbach's Alphas for the SSBD Critical Events, Adaprive Behavior, and Maladaptive Behavior scales for the study sample were $.76, .89$, and .90 , respectively. Kindergarten and fitst grade children whose scores fell within the 21 st to 30 th percentile range of national norms on the ESP or SSBD were enrolied in the Universal group; whereas, those whose scores were equal to or less than the 20 th percentile were enrolled in the Selected intervention group. The mean number of trearment days for children in the Selected intervention group was $31.06(S D=3.19)$.

Children were entolled in the Indicated intervention group if they were currently receiving special educacion services for emotional disturbance or had a DSM-IV diagnosis, exhibiting behaviors that were symptomatic of a serious mental health problem (scores in the borderline to clinical range on the Child Behavior Checklist or the Teacher Report Form; Achenbach, 2001), and/or in need of special service coordination across two or more service systems or agencies. The mean number of treatment days for children in the Indicated intervention group was 215.36 (SD = 76.69).

Participant demographic characteristics (i.c., gender, free/reduced lunch status, race) for the Universal, Selected, and Indicated groups are presented in Table l. Overall, a majority of the participants were males $(68 \%)$ and received free or reduced lunch (66\%). The race of children was based on the designations provided by parents/guardians and for several children more than one racial preference was identified. The overall race breakdown of the children included 327 (80\%) Caucasians, 84 (21\%) African Americans, $38(9 \%)$ Hispanics/Larinos, $20(5 \%)$ Native Americans, 7 (2\%) Asian Americans, and 3 (1\%) Hawaiian/Pacific Islanders. Seventy-iwo parent/guardians identified more than two races. The mean ages of children in the Universal, Selected, and Indicated groups at study intake were 5.83 $(S D=0.59), 6.31(S D=0.63)$, and $7.44(S D=$ 1.07), respectively. 


\begin{tabular}{|c|c|c|c|c|c|c|}
\hline \multirow[b]{3}{*}{ Age in Years (SD) } & \multicolumn{6}{|c|}{ Group } \\
\hline & \multicolumn{2}{|c|}{$\begin{array}{l}\text { Universal } \\
(\mathrm{n}=153)\end{array}$} & \multicolumn{2}{|c|}{$\begin{array}{c}\text { Selected } \\
(\mathrm{n}=173)\end{array}$} & \multicolumn{2}{|c|}{$\begin{array}{l}\text { Indicated } \\
(\mathrm{n}=81)\end{array}$} \\
\hline & 5.6 & $(0.6)$ & 6.3 & $(0.6)$ & 7.5 & $(I . I)$ \\
\hline Demographic & $N$ & $\%$ & $\mathbf{N}$ & $\%$ & $\mathrm{~N}$ & $\%$ \\
\hline \multicolumn{7}{|l|}{ Gender } \\
\hline Male & 92 & 60 & 116 & 67 & 69 & 85 \\
\hline Female & 61 & 40 & 57 & 33 & 12 & 15 \\
\hline Free/Reduced Lunch & 89 & 58 & 119 & 69 & 57 & 70 \\
\hline \multicolumn{7}{|l|}{ Race $^{2}$} \\
\hline African American & 29 & 19 & 33 & 20 & 22 & 26 \\
\hline Asian & 2 & 1 & 3 & 2 & 2 & 2 \\
\hline Hawaiian/Pacific Island & 0 & 0 & 1 & $<1$ & 2 & 2 \\
\hline Hispanic/Latino & 19 & 12 & 16 & $\mathfrak{9}$ & 3 & 4 \\
\hline Native American & 6 & 4 & 11 & 7 & 3 & 4 \\
\hline Caucasian & 124 & 79 & 135 & 80 & 68 & 80 \\
\hline
\end{tabular}

Note. ${ }^{2}$ Numbers and percentages are based on the overall parent/guardian reports of race provided. Seventy-two parent/guardians identified more than two races.

STUDY DESIGN AND

\section{THREE-TIER BEHAVIOR MODEL}

A quasi-experimental cohort longitudinal design was used to assess the effeces of the threc-rier behavior model. Each of the four cohorts of children was enrolled in the present study each respective project year (see Table 2). Inspection of Table 2 reveals that pre- and postintervention data were collected in the fall (Time 1) and spring (Time 2) for all four cohorts of children. One (Time 3) and two (Time 4) year follow-up daca (spring) were collected on Cohorts 1 to 3 and Cohorts 1 to 2, respectively. Children in the Selected and Indicated intervention groups received their respective interventions in the first year (between Time 1 and Time 2). Universal, Selected, and lndicated intervention groups received the universal intervention continuously over the assessment timeframes.

\section{Universal Program (BASE)}

Description. BASE included three primary elements: (a) common area procedures and behavioral expectations, (b) the Think Time Strategy (a consistent classroom managernent strategy applied schoolwide), and (c) a continuum of administrative disciplinary responses. The common areas procedures were designed to promote positive

TABLE 2

Assessment Timeframe by Cobort

\begin{tabular}{lcccc}
\hline & \multicolumn{4}{c}{ Assessment Timeframe } \\
\cline { 2 - 5 } Cohort/Year & Time 1 & Time 2 & Time 3 & Time 4 \\
\cline { 2 - 5 } 1 & Fall 2002 & Spring 2003 & Spring 2004 & Spring 2005 \\
2 & Fall 2003 & Spring 2004 & Spring 2005 & Spring 2006 \\
3 & Fall 2004 & Spring 2005 & Spring 2006 & \\
4 & Fall 2005 & Spring 2006 & & \\
\hline
\end{tabular}


student behavior. For example, the lunch/recess schedule was designed to reduce wait time in the lunch line and maximize the level of supervision (see Martella, Nelson, \& Marchand-Marrella, 2003 for a complete description of the elements and implementation of BASE). Established patterns of supervision were also developed to enable staff to provide a more complete and balanced coverage of the common areas. In addition to procedures, behavioral expectations for each common area were developed and taught to children. The focus was on arrival, lunch/recess, and dismissal because a majority of the problems occur in these areas. Teachers actively taughe children the routines and rewarded students for following them (e.g., lunch with the principal, stickers). Periodic reviews of the routines were then conducred throughour the remainder of the year at critical times (e.g., following extended breaks).

The Think Time Strategy (Nelson \& Carr, 2000) was implemented schoolwide. The Think Time Srrategy provided the basis for a more collaborative and less confrontational classroom management approach. Instcad of reinforcing disruptive behavior by using punitive measures, 'The Think Time Strategy is designed to help staff facilicate corrective social interaction patterns and emotional experiences as well as enhance children's self-regulation skills (i.e., control of impulses and cmotions). Specifically, the Think Time Strategy is a collaborative process among two or more teachers (e.g., the homeroon teacher and a cooperating reacher(s) who provide the designared Think Time area). The Think Time Straregy includes three components: (a) precision request (i.e., teacher uses a short verbat statement to encourage the child to exhibit positive social behavior and does not use threats, ultimatums, warnings, or repeared request); (b) scudent reflective period (i.e., student gains self-control); and (c) behavioral debriefing process (i.e., teacher checks for self-control and initiares a positive interaction with the child).

The continuum of administrative disciplinary responses included those commonly used by schools (c.g., lunch rime derention, performance-based in-school suspension, out-of-school suspension) as well as an administrative student reflecrive period (i.c., student gains self-control) and debriefing intervention. The administrative student reflective periods and debriefing interven[jor] was the primary administrative disciplinary response used by school staff. This disciplinary response was applied when children were noncompliant of highly disruptive during Think Time. The rolc of the administrator was to simply deescalare and help the student gain self-control. The role of the teacher was to ensure that the student completes Think Time stuccessfully following the administrarive student reflective periods and debriefing intervention. These coordinated administrator-teacher roles ensured that reacher authority was maincained.

Implementation. Implementation of BASE was achieved chrough a representative leadership ream at cach school. The leadership ream included the principal, school psychologist, general education reacher and special education team leaders, and a communiry representative. The leadership tean participated in a 6 -hr workshop designed ro enhance their knowledge and comperencies in the BASF model. The training content included (a) overview of primary-level school organizational systems (c.g., leadership, schoolwide, nonclassroom, classroom); (b) specific elements of primary-level school organizational systems; (c) explanarion of how the School Evaluation Rubric (SER) is used to cvaluate the school's current status (c.g., beginning, developing, exemplary) and service gaps (i.e., specific elements within each organizational system thar need ro be added or revised); and (d) implementation procedures and strategies of BASE.

The SER encompasses a three-step planning model ro develop and implement BASE. First, the leadership team conducted a consensus-based administrarion of the SER (approximately $1 \mathrm{hr}$ ) with all staff to identify the current status of the schoolwide discipline program and to identify service gaps. Second, based on the results of the SER, the leadership team met three times (approximately $8 \mathrm{hr}$ ) to develop a strategic implementation plan. Finally, the leadership team guided the implementation of each of the components of the schoolwide discipline program across the remainder of the school year and continued to monitor its effectiveness and make adjustments as necessary over the projecr years. Project staff held collaborative problem-solving meetings with the school's leadership team when necessary. In addi- 
tion, a half-day training session and three problem+solving meetings were conducted on the Think Time Strategy (Nelson \& Carr, 2000) and associated administracive disciplinary responses with staff. The content was as follows: (a) theoretical model (social learning theory); (b) preventative classroom management (e.g., reaching expectations); (c) key elements (precision request, student reflective period, debriefing); (d) implementation steps; (e) use with administrative discipline procedures; and ( $f$ ) common questions.

\section{Selected Program (First Step to Success)}

Description. First Step to Success consists of three modules implementing a series of activities designed to be applied in concert with each other. The modules include (a) proactive, universal screening of all kindergarten and first grade populations; (b) consultant-based school interventions involving the target child, peers, and teachers; and (c) parent training in caregiver skills for supporting and improving the child's school adjustment performance in the home. A description of each module follows.

Screening Module. The screening module was previously described in detail. As noted, kindergarten and first grade children in the Selected inrervention group met the respective specified ESP and SSBD criteria.

School Module. The school module of First Srep to Success is an adapted version of the CIASS (Contingencies for Learning Academic and Social Skills) program for the Acting-Out Child developed by Hops and Walker (1988). CLASS is divided into three successive phases: consultant, teacher, and maintenance. The consultant phase begins with a daily 20 -min session with the child, called the green-red card game. Initially, the consultant, in close proximity, monitors the target child's classroom behavior using a green and red card. During this time, there are random moments when the behavioral coach will check if the card is displaying green or red. If the card is on green, the child will earn a poinc. To meet criterion, the child must earn a minimum of $80 \%$ of the possible points for the session. When the child meets the criterion, she earns a previously arranged classroom reward, such as playing a game with the whole class. The child will also earn a special reward activity with her parents at home. The parents are given daily feedback regarding their child's progress and are encouraged to provide home activities, such as reading a book or playing a game as a reward for the child meering the criterion at school. As the game progresses, the session length becomes longer and the interval in which points and praise can be earned is gradually extended from $30 \mathrm{~s}$ to $10 \mathrm{~min}$. Also, in later stages of the program, the target child must work in blocks of multiple days in order to earn a reward. Thus, the progran becomes more demanding as the student progresses through it, and the student must sustain acceptable performance for progressively longer periods of time in order to be successful.

The "teacher phase" (Program Days 6-20) is operated by the classroom reacher in whose room the program is inirially implemented. The teacher assumes control of the program's operation on Program Day 6, but with close supervision and support provided by the First Step to Success coach. The consultant provides monitoring and technical assistance on an as-needed basis for the teacher throughout the temainder of the reacher phase. Teacher phase implementation tasks include (a) operating the program daily, (b) awarding praise and points according to program guidelines contingent on the child's performance, (c) supervising delivery of group acriviry and school rewards, and (d) communicating with parents on a regular basis regarding the rarger child's performance. The teacher works closely with the child, behavioral coach, parents, and peers throughout the total implementation period.

In the "maintenance phase" (Program Days $21-30$ ), the targer child is rewarded primarily with praise and expressions of approval/recognition from the teacher at school and the parencs ar home. An arrempr is made during this phase to reduce the child's dependence on the program by substituring adult praise for points, reducing the amount of daily feedback given, and making occasional rewards available contingent on exemplary performance. In the majority of the cases, target children who successfully complete the teacher phase of the program are able to susrain their improved behavior in this phase despite these program changes.

Home Module. The home module (HomeBase) consists of a series of six lessons designed to 
enable parents and caregivers ro build child competencies and skills in six areas that affect school adjustment and performance: (a) communication and sharing in school, (b) cooperation, (c) limit setting, (d) problem solving, (e) friendship making and (f) development of confidence. HomeBase contains lessons, instructional guidelines, and parent-child games and activities for teaching these skills. HomeBase requires 6 weeks for implementation and begins after the target child has completed Program Day 10 of the First Siep to Success program. The First Step to Success behavioral coach visits the parent's home weekly to conduct the HomeBase lessons. Following each session, macerials are left with the parents that tacilitate daily review and practice of each skill with the target child. The HomeBase lessons require approximately 1 hr edch. Parents are encouraged to work with their children 10 to $15 \mathrm{~min}$ daily and to focus on practicing the HomeBase skills being taught.

Implementation. Prior to implcmentation, the behavioral coaches attended a G-day training session. (Note that length and intensiveness of the training session exceeded what is rypically used to implement First Step to Success.) The training session content included (a) the underlying principles of First Step to Success; (b) research regarding serious EBD; (c) screening procedures for identifying children eligible for First Step to Success; (d) the role of the child, teacher, parent, and coach with regard to implenenting First Step to Success; (c) discussion of training video content; and $(\hat{f})$ role-playing the duties of a behavioral coach (c.g., conducring initial child meetings, starting the program in the classroom, and using the green/red card appropriately).

After the initial training session, a 2-day training on the HomeBase module was conducted. The HomeBase training content included (a) review of the six lessons delivered to parents regarding improving home and school interactions; (b) review of the parent and child activities presenred in the HoncBase materials; and (c) discussion of common questions asked by parents during HomeBase sessions. In addition to presencations and discussions, role-plays were used for the coaches to practice conducting the home sessions.
Finally, rwo single-day booster trainings were scheduled for the First Srep ro Success project staff. One booster session occurred in the fall as implementation was beginning, and the other in the winter after the first group of children had completed the program. This training consisted of a review of First Step to Success, along with a rrouble-shooting session to discuss questions regarding implementation. Throughout early implementation of First Step to Success, ongoing discussions via e-mail and phone berween project staff and the First Step to Success program developer regarding implementation issues were used to solve implementation issues. Likewise, weekly First Step to Success team meetings occurred throughout the project. These meetings included the supervisor and behavioral coaches. The weekly meetings provided an opportuniry to discuss implementation concerns, solve difficult implementation issues, and overcome obstacles to consistently implement First Step to Success.

\section{Indicated Program (MST)}

Description. MST views individuals as being surrounded by a nerwork of interconnected systems that encompass individual, family, and extrafamilial (pecr, school, neighborhood) factors and recognizes that successful intervention requites a combination of these systems. The primary goals of MST are co (a) reduce the frequency and severity of mental health problems, (b) reduce other types of antisocial behavior, and (c) achieve these outcomes at a cost savings by decreasing rates of incarceration and our-of-home placemerts. MST achieves these goals through adherence to nine treatment principles.

1. The primary purpose of assessmenc is to understand the fit between the identified problems and their broader systemic context.

2. Therapeutic contaces emphasize the positive and use systemic strengths as levers for change.

3. Interventions are designed to promote responsible behavior and decrease ir responsible behavior among family members.

4. Interventions are present focused and accion uriented, targering specific and well-defined problems. 
5. Interventions target sequences of behavior within and between multiple systems that maintain the identified problems.

6. Interventions are developmentally appropriate and fit the developmental needs of the children.

7. Interventions ate designed to require daily or weekly effort by family members.

8. Intervention effectiveness is evaluated continuously from multiple perspectives with providers assuming accountability for overcoming barriers to successful outcomes.

9. Interventions are designed to promote treatment generalization and long-term maintenance of therapeutic change by empowering caregivers to address family members needs across multiple systemic contexts.

Key characteristics of this model are (a) low caseloads, typically three to six families per fulltime therapist; (b) provision of services in the family's natural environment-home, school and neighborhood settings; (c) time-limited duration, 3 to 5 months of treatments per family depending on the seriousness of the problems and successes of the incerventions; (d) therapist functioning within a team of three to four practitioners, though each has an individual caseload; (c) 24hour $/ 7$-days per week availability of therapists or at least one practitioner on the MST team; (f) scheduling appointments at the family's convenience, such as evening hours and weekends; and (g) daily contact, in person or by phone, with families.

Each MST therapist was assigned a caseload of 4 to 6 children across the elementary schools. The therapist then met with the family to conduct an ecological assessment that (a) identified the primary presenting problems, (b) developed a treatment plan that lists family short- and longterm trcatment goals, (c) identified strategies to accomplish the goals, and (d) determined barriers to successful implementation. Therapists met in person with families several times a week and had frequent telephone contact with families as well. The therapists also met with each child's teacher, school administrators, and orher school personnel to identify school-reiated problems, to design school-based intervention strategies, and to iden- tify barriers to successful implementation. Thetapists met every 3 weeks with the child's teacher and regularly monitored school performance through regular telephones and e-mails.

Implementation. Three MST therapists were hired by the project to implentent the program in the target school. The MST therapists had master's degrees and experience with children with mental health disorders. The therapists were supervised by a state-certified clinical rherapist. The MST therapists and supervisor underwent specific training and supervision as indicated by the developers of MST. A 1-day scaling-up training session was conducted by staff from MST Services. The audience included (a) the MST supervisor, (b) key staff from the local mental health center, (c) community leaders including local school district administrators and mental health agency administrators, and (d) two to three representatives from each of the participating schools. The training content included (a) an overview of MST including the scope, correlates, and causes of the serious behavior problems addressed with MST; (b) the theoretical and empirical underpinnings of the treatment model; and (c) a description of the family, peer, school, and individual intervention strategies used.

Prior to beginning the study, the MST therapists and supervisor attended a 5-day MST training session that included didactic and experiential components. Didactic components consisted of (a) systems theories, social learning theory, and major psychological and sociological models; (b) research regarding serious emotional disturbance in youth; (c) research relevant to problems experienced by target youth (e.g., learning disabilities); and (d) research on interventions used in MST (e.g., empirically validated family and marital therapy approaches). In addition, the training included (a) role-plays and exercises designed to stimulate critical thinking about the treatment process; (b) client engagement; (c) individual, family, and systems-level assessments; (d) evaluation of evidence used to draw conclusions about the correlates/causes of a problem; (e) the development of intervention strategies and specific interventions; and $(f)$ how to derermine whether an intervention is being effective.

Two-day quarterly booster trainings were provided throughour the project period by a con- 
sultant from MST Services. As therapists gained field experience with MST, quarterly booster sessions were conducted on site. These boosters provided additional training in areas identified by therapists (e.g., marital interventions, treatment of parencal depression in the context of MST) and facilitated in-depth examination and problem solving of particularly difficult cases. MST consultants were responsible for designing and delivering the booster training.

Weekly relephone consultation was also provided by MST Services. The 1-hr consultations were provided by the MST consultant assigned to the project and the co-developer of MST. Consultarion sessions focused on promoring adherence to MST treatment principles, developing solutions to difficult clinical problems, and designing plans to overcome any barriers to obraining strong treatment adherence and favorable outcomes for youths and families.

\section{DEPENDENT MEASURES}

Social Bebavior. The reacher forms of the Social Skills Rating System (SSRS; Gresham \& Elliot, 1990) Problem Behavior and Social Skills scales were used to measure the social behavior of children. The Problem Behavior and Social Skills rating scale contain 18 and 30 items, respectively. Raters are asked to consider "how often" $10=$ never, 1 = sometimes, 2 = very often) a problem behavior or social skill is observed. The SSRS has demonstrated excellent psychometric characteristics across diverse samples (Bracken, Keith, \& Walker, 1994; Demaray \& Ruffalo, 1995; Merrell $\&$ Gimpel, 1998). The reported internal consistency and test-retest reliabilities for the Problem Behavior and Social Skills scales were .82 and .94 and .85 and .84 , respectively (Gresham $8 \mathrm{El}$ liott). The internal consistency reliabilities for the Problem Behavior and Social Skills scales for the study sample were .93 and .88 , respectively.

Academic Competence. The teacher form of the SSRS Academic Competence scale (Gresham \& Elliort, 1990) was used to measure the academic competence of children. The SSRS Academic Competence scale includes nine items presented on a 5 -point scale ( $1=$ lowest $10 \%, 2=$ next lowest $20 \%, 3=$ middle $40 \%, 4=$ nexc highest $20 \%, 5=$ highest $10 \%$ ). The reported internal consistency and test-retest reliabilities for the Academic competence scale were .95 and .93 , respectively (Gresham \& Elliott).

Word Reading Skills. The Woodcock Reading Mastery Test-Revised/Normative Update (WRMTR/NU; Woodcock, 1998) Basic Reading Skills Cluster was used to measure the word reading skills of children. This cluster is comprised of the Word Attack and Word Identification subrests. The Word Attack test includes 50 nonwords that increase in difficulty. The Word Identification subrest consists of 106 words that increase in difficulty. Split-half reliabilities for the Word Atrack and Word Identification subtests are .94 and .98, respectively (Woodcock).

\section{TREATMENT INTEGRITY \\ MEASURES}

A 5-point convergent evidence scale (Busse \& Elliott, 2001) was created to provide a consistent caregorization of the extent to which the universal, selected, and indicated intervention programs were implemented ( $1=$ poor implementation, 2 = limited implementation, 3 = adequate implementation, $4=$ good implementacion, and $5=$ excellent implementation). A description of the treatment integricy measures and associated categorization of treatment implementation for the universal, selected, and indicated programs follows.

Universal Program (BASE). A staff survey was used ro assess fidelity of implementation for BASE. Each project year staff members at each of the seven schools were asked to complete an eight-item questionnaire regarding whether the BASE implementation phase was followed. Staff rated each item on a 3-point Likert type scale (i.e., low, medium, high). Each staff member completed the questionnaire independently in the second month of the school year. The eight items focused on key elements of BASE (e.g., extent to which staff taught and reviewed the common area and disciplinary procedures with children, communicated with parents about expectations, applied active supervision). Corresponding mean aggregate survey criterion score ranges (i.e., total scale score range $=8$ to 24 ) for poor, limited, adequate, good, and excellent implementation on the convergent evidence scale were $<12,12$ to $<16$, 
16 to $<18,18$ to $<22$, and $>22$, respectively. Each school was assigned a convergent evidence scale score ranging from 1 (poor implementation) to 5 (excellent implementation).

Selected Program (First Step to Success). Five measures were used to assess treatment fidelity for First Step to Success.

1. Independent observations by project of staff of whether the coach implemented (i.e., occurred, did not occur) 18 components of the green/red card game (e.g., operating the program daily, awarding praise and points according to program guidelines contingent on child performance).

2. Seven-irem checklist completed by the teacher focusing on the green/red card game quality of implementation,

3. Five-item Likert-type 5-point rating scale (ranging from poor to excellent implementacion) by the coach of the teacher phase of the game (e.g., operating the game, rate of ptaise, awarding of reward following completion of the game).

4. Daily program logs of school-to-home communication (e.g., daily communication with parent, parent signature on red/green card).

5. Coach self-reported checklist of the elements of the HomeBase component (e.g., the length of the session, number of activities complered by the parent and child during the week).

The mean aggregate criterion score for the five measures were used to create a 5-point composite scale ranging from +2 to -2 . The mean composite score ranges for poor, limited, adequate, good, and excellent implementation on the convergent evidence scale were $<-1.5,-1.4$ to $-.5,-.4$ to .4 , .5 to $1.4,>1.4$, respectively. Each child was assigned a convergent evidence scale score ranging from 1 (poor irriplementation) to 5 (excellent implementation).

Indicated Program (MST). The Therapist Adherence Measure (TAM) was used to assess fidelity of implementation for MST. The TAM is a 26-item Likert-format measure that assesses a therapist's adherence to the MST model as reported by the primary caregiver of the family. The
TAM was administered during the second week of therapy and approximately every 4 weeks thereafter. The TAM measures three adherence factors: (a) family-therapist collaboration, (b) atrempts to change intra- and extrafamilial interactions, and (c) follow-up treatment progress. Corresponding TAM aggregate criterion score ranges for poor, limited, adequate, good, and excellent implementation on the convergent evidence scale were $<0,0$ to $.39, .40$ to $.50, .51$ to .79 , and $>.80$, respectively. Each child was assigned a convergent evidence scale score ranging from 1 (poor implementation) to 5 (excellent implementation).

\section{RESULT}

\section{TREATMENT FIDELITY}

Universal Program (BASE Treatment Fidelity). The overall staff mean convergent scale score of the extent to which the universal program was implemenced was $4.0(S D=0)$, indicating "good" implementation. There was no variation in the level of implementation responses across the schools or project years.

Selected Program (First Step to Success) Treatment Fidelity. Treatment fidelity data were collected at least once for each child who received the selected program. The overall mean convergent scale score of the extent to which the selected intervention was implemented was 3.95 ( $S D=$ 48), indicating adequate-to-good implementation. The extent to which the selected intervention was implemented among children and their families was relatively consistent (range $=3$ to 5).

Indicated Program (MST) Treatment Fidelity.

Treatment fidelity data were collected at least once for each child who received the indicated program. The overall mean convergent scale score of the extent to which the indicated intervention was implemented was $2.2(S D=1.33)$, indicating limited implementation. The extent to which the indicated intervention was implemented among children and their families varied widely (range = 1 to 5). 
EFFECTS OF THREE-TIER

\section{BEHAVIOR MODEL}

Two-level linear growth analyses were conducted with each of the two social behavior scales (SSRS Problem Behavior and Social Skills) and two academic competence measures (SSRS Academic Competence scale, WRMT-R/NU Basic Reading Skills cluster). All analyses were conducted with the Hierarchical Linear Modeling (HLM) statistical package (Raudenbush, Bryk, Cheong, \& Congdon, 2004). The first level of the linear growth analysis modeled individual student growth trajectories to a linear variable across four data assessment points called TIME that yielded two results: a $y$-intercept and the slope over TIME. The second level modeled the effects of selected covariates that may influence outcomes for students at risk for EBD (i.e., age, gender, ethnic diversity, free lunch status), as well as the selected and indicated intervention program variables on the $y$-intercept and slope over TIME. Children were assessed at four different time points measured actoss 4 years: TIME 1, preintervention (fall, Year 1); TIME 2, postintervention (spring, Year 1); TIME 3, follow-up 1 (spring, Year 2); and TIME 4, follow-up 2 (spring, Year 3). The assessment timeframe by cohort is presented in Table 2. Two separate analyses were conducted for each outcome variable that modeled two different pieces of the linear variable TIME: Pre- to postintervention and postintervention through followup. The first piece of the analyses determined the effects of the students' trajectory and was centered at the end of the intervention at TIME 2 (i.e., piece-1, TIME $=-1,0,0,0)$. Therefore, the piece-1 analysis tested the $y$-intercept at TIME 2 and the slope from pre- to postintervention with the pooled variance including the follow-up time points. We used this pooled variance term as it is a more conservative statistical test because it tests for the explained variance at TIME 2 including the variance across the follow-up time points. The second piece was also centered at the end of intervention bur included two follow-up data points (i.e., piece-2, TIME $=0,0,1,2$ ). Therefore, the piece- 2 analysis tested the $y$-intercept at TIME 2 and the change across the two follow-up points, although the intercept included the pretest variance. Again, we used this pooled variance term as we believe it is a mote conservative statistical test because it tests for the explained variance ar TIME 2 including the variance from the pretest.

For each outcome measure the Level-1 Model was a linear growth model across TIME depicted in the following using the HLM output equation:

\section{Level-1 Model \\ $\mathrm{Y}=\mathrm{PO}+\mathrm{P} 1 \times(\mathrm{TIME})+\mathrm{E}$}

The ourcome variable $(\mathrm{Y})$ was predicted as a function of the $y$-intercept ( $\mathrm{P} 0$ ) centered at Time 2 $(-1,0,0,0)$, and the linear slope in scores actoss time (P1 3 TIME), as well as the error (E) in that prediction. A second piece analysis was conducted with the ourcome variable $(Y)$ predicted as a function of the $y$-intercept $(\mathrm{P} 0)$ centered at Time $2(0$, $0,1,2)$ but with the inclusion of the two followup data points.

The Level-2 model tested the added effects of four covariates (i.e., age, male, non-White, free lunch status) as well as the added intervention effects of the student receiving the selected or indicated interventions compared to students who just received the Universal program alone.

\section{Level-2 Model}

$$
\begin{aligned}
& \mathrm{P} 0=\mathrm{B} 00+\mathrm{B} 01 \times(\text { age })+\mathrm{B} 02 \times(\text { male })+ \\
& \mathrm{B} 03 \times(\text { non }-\mathrm{Wh} \text { hite })+\mathrm{B} 04 \times(\text { free lunch })+ \\
& \mathrm{B} 05 \times(\text { selected })+\mathrm{B} 06 \times(\text { indicated })+\mathrm{R} 0 \\
& \mathrm{P} 1=\mathrm{B} 10+\mathrm{B} 11 \times(\text { age })+\mathrm{B} 12 \times(\text { male })+ \\
& \mathrm{B} 13 \times(\text { non-White })+\mathrm{B} 14 \times(\text { free lunch })+ \\
& \mathrm{B} 15 \times(\text { selected })+16 \times(\text { indicated })+\mathrm{R} 1
\end{aligned}
$$

The effect on students' individual growth at the Time 2 intercept ( $\mathrm{PO}$ ) was a function of the Universal program effect at the intercept (B00) plus the effects of the covariates (B01, B02, B03, and $B 04)$ and whether the student received the Selected (BO5) or the Indicated (B06) interventions, along with the error in this predicrion (R0).

The effect on students' growth over 'TIME (P1) was a function of the Universal program effect at the intercept (B10) plus the effects of the covariates (B11, B12, B13, and B14) and whether the student recejved the Selected (B15) or the Indicated (B16) intervention, along with the error in this prediction (R1). In addition, the random effects of model about the $y$-intercept and growth were modeled. 
TABLE 3

Linear Change on Problem Behavior From Pre- to Postintervention and Postintervention Through Follow- $U p$

\begin{tabular}{|c|c|c|c|c|c|c|}
\hline \multirow[b]{2}{*}{ Fixed Effect Variables } & \multicolumn{3}{|c|}{ Preintervention to Postintervention } & \multicolumn{3}{|c|}{ Postintervention Through Follow- $U_{P}$} \\
\hline & Coefficient & Error & T-ratio & Coefficient & Error & T-ratio \\
\hline Universal Intercept & $102.508^{* * *}$ & 4.86 & 21.092 & $102.099^{* * *}$ & 4.29 & 23.746 \\
\hline Age & 0.470 & 0.85 & 0.554 & 0.488 & 0.77 & 0.631 \\
\hline Male & -0.336 & 1.14 & -0.296 & -0.802 & 1.15 & -0.696 \\
\hline Non-White & 1.789 & 1,19 & 1.508 & 1.311 & 1.18 & 1.111 \\
\hline Free lunch & $2.370^{*}$ & 1.12 & 2.124 & 1.054 & 1.11 & 0.946 \\
\hline Selected Treatment & $6.833^{* * *}$ & 1.29 & 5.315 & $10.390^{* * *}$ & 1.36 & 7.652 \\
\hline Indicared Treatment & $12.282^{* * * *}$ & 2.14 & 5.739 & $15.583^{* * *}$ & 2.17 & 7.175 \\
\hline Universal Slope & -4.339 & 4.974 & -0.872 & 2.509 & 4.029 & 0.623 \\
\hline Age & 0.715 & 0.853 & 0.839 & -0.421 & 0.683 & -0.617 \\
\hline Male & 0.509 & 1.049 & 0.485 & 0.593 & 0.826 & 0.718 \\
\hline Non-White & 0.251 & 1.171 & 0.215 & 0.365 & 0.869 & 0.420 \\
\hline Free lunch & 1.874 & 1.084 & 1.728 & 1.094 & 0.846 & 1.293 \\
\hline Selected Treatment & $-5.836^{* * *}$ & 1.257 & -4.642 & $-2.437^{*}$ & 0.956 & -2.548 \\
\hline Indicated Treatment & $-5.592^{*}$ & 2.242 & -2.494 & -2.073 & 2.049 & -1.012 \\
\hline
\end{tabular}

${ }^{*} p<.05 .{ }^{* * *} p<.001$.

The overall numbets of children at each measurement point were $N_{\text {Tims1 }}=407, N_{\text {Time2 }}=369$, $N_{\text {Time3 }}=291$, and $N_{\text {Time4 }}=190$. The number of children in each group were (a) Universal, $n_{\text {Timel }}=$ $153, n_{\text {Time } 2}=147, n_{\text {Tink3 }}=109$, and $n_{\text {Time4 }}=78$; (b) Selected, $n_{\text {Time1 }}=173, n_{\text {Time } 2}=165, n_{\text {Time3 }}=$ 149 , and $n_{\text {Times }}=112$; and (c) Indicated, $n_{\text {Timel }}=$ $81, n_{\text {Time2 }}=57, n_{\text {Tinne }}=33, n_{\text {Time4 }}=0$. Note that with the HLM data analytic approach used, the students' linear growth was estimated from the reliability of the data with respect to the number of observations and variability of observations for each student so that lower reliability estimates result in esrimates based on the group's data. Therefore, missing data is handled with an optimally weighted composite of the individual and group sources of information.

All Level-1 model results for individual students' linear growth on each of the outcome measures was statistically significant $(p<.001)$ for the $y$-intercept (P0) and slopes (P1), indicating that all students' posttreatment scores were significantly greater than zero and that they showed significant change in their scores across the assessment periods analyzed. The results of Level2 models are reported for each of the linear growth analyses conducted in Table 3 through Table 6.

\section{EFFECTS ON PROBLEM BEHAVIOR}

Pre- to Postintervention. The results of the linear growth analyses for the pre- and postintervention as well as the postintervention and follow-up for the SSRS Problem Behavior scale are presented in Table 3. For pre- to postintervention, the group that received only the Universal program ended with a standard score of 102 , which was statistically different from zero (Coefficient $=$ $102.5, S E=4.86, p<.001)$. The free lunch covariate was statistically significant (Coefficient = $2.37, S E=1.12, p<.001)$ and indicated that students with this status ended treatment 2.37 standard score points above students just receiving the Universal program at 105 . The Selected intervention group ended treatment statistically higher than the Universal group (Coefficient $=6.8, S E=$ $1.29, p<.001$ ) with an estimated standard score of 109. The Targeted incervention group ended treacment statistically higher than the Universal group $($ Coefficient $=12.3, S E=2.14, p<.001$ ) with an estimated standard score of approximately 115 . 
TABLE 4

Linear Change on Social Skills From Pre-to Postintervention and Postintervention Through Follow-Up

\begin{tabular}{|c|c|c|c|c|c|c|}
\hline \multirow[b]{2}{*}{ Füed Effect Variables } & \multicolumn{3}{|c|}{ Preintervention to Postintervention } & \multicolumn{3}{|c|}{ Postintervention Through Follow- $U_{p}$} \\
\hline & Coefficient & Error & T-ratio & Coefficient & Error & T-ratio \\
\hline Universal [ntercept & $97.442^{* * * *}$ & 4.781 & 20.378 & $97.334^{* * *}$ & 4.387 & 22.189 \\
\hline Age & -0.118 & 0.824 & -0.144 & -0.267 & 0.784 & -0.341 \\
\hline Male & -1.123 & 1.184 & 0.949 & 1.627 & 1.183 & 1.375 \\
\hline Non-White & -0.920 & 1.229 & -0.748 & -0.499 & 1.251 & -0.399 \\
\hline Free lunch & -1.638 & 1.180 & -1.387 & -0.969 & 1.173 & -0.827 \\
\hline Selected Treatment & $-5.415^{* * *}$ & 1.303 & -4.157 & $-8.596^{* * *}$ & 1.413 & -6.085 \\
\hline Indicated Treatment & $-8.559^{* * *}$ & 2.421 & -3.536 & $-11.706^{* * *}$ & 2.318 & -5.050 \\
\hline Universal Slope & -6.380 & 5.277 & 1.209 & -3.674 & 4.156 & -0.884 \\
\hline Age & $-0.87 \mathrm{t}$ & 0.909 & -0.958 & 0.781 & 0.716 & 1.090 \\
\hline Male & -0.415 & 1.311 & -0.317 & -0.812 & 0.879 & -0.924 \\
\hline Non-White & -0.299 & 1.358 & -0.220 & -0.305 & 0.953 & -0.320 \\
\hline Free lunch & -1.358 & 1.305 & -1.040 & -0.262 & 0.917 & -0.285 \\
\hline Selected Treatment & $6.326^{* * *}$ & 1.447 & 4.373 & $2.229^{*}$ & 1.039 & 2.146 \\
\hline Indicated Treatment & $7.388^{* *}$ & 2.656 & 2.782 & 1.810 & 2.539 & 0.713 \\
\hline
\end{tabular}

${ }^{*} p<.05 .{ }^{* *} p<.01 .^{* * *} p<.001$.

The slope from pre- to postintervention showed that the Selected intervention group significantly changed (Coefficient $=-5.8, S E=1.26$, $p<.001)$. This suggests that students in this group decreased approximately 6 points from preto postintervention. Therefore, using the postin- tervention estimate and the change from preintervention would suggest that the students in the Selected incervention group changed from a score of 115 to 109 . The lndicated intervention group also showed a significant change in problem behavior (Coefficient $=-5.59, S E=2.24, p<.05$ ),

TABLE $\mathbf{5}$

Linear Change on Academic Skills From Pre- to Postintervention and Postintervention Through Follow-Up

\begin{tabular}{|c|c|c|c|c|c|c|}
\hline \multirow[b]{2}{*}{ Fixed Effect Variables } & \multicolumn{3}{|c|}{ Preintervention to Postintervention } & \multicolumn{3}{|c|}{ Postintervention Through Follow-Up } \\
\hline & Coefficient & Error & T-ratio & Coefficient & Error & T-ratio \\
\hline Universal Intercept & $92.048^{* \pm t}$ & 4.88 & [ 8.878 & $90.958^{* * *}$ & 4.842 & 18.784 \\
\hline Age & 0.051 & 0.80 & 0.064 & 0.237 & 0.800 & 0.296 \\
\hline Male & 0.361 & 1.11 & 0.326 & -0.608 & 1.182 & -0.514 \\
\hline Non-White & $-1,110$ & 1.20 & -0.921 & -0.766 & 1.255 & -0.610 \\
\hline Free lunch & $-5.514^{* * *}$ & 1.170 & -4.712 & $-6.655^{* * *}$ & 1.206 & -5.519 \\
\hline Selected Treatment & $-2.871^{*}$ & 1.225 & -2.345 & $-2.808^{*}$ & 1.345 & -2.087 \\
\hline Indicated Trearment & -3.797 & 2.587 & -1.467 & -3.965 & 2.357 & -1.683 \\
\hline Universal Slope & 3.520 & 3.226 & 1.091 & -0.139 & 2.674 & -0.052 \\
\hline Age & -0.590 & 0.532 & -1.109 & -0.005 & 0.440 & -0.012 \\
\hline Male & 0.889 & 0.729 & 1.220 & 0.799 & 0.582 & 1.373 \\
\hline Non-White & -0.275 & 0.782 & -0.352 & -0.404 & 0.643 & -0.628 \\
\hline Free lunch & 0.335 & 0.785 & 0.426 & $1.504^{*}$ & 0.619 & 2.427 \\
\hline Selected Treatment & 1.434 & 0.822 & 1.744 & -0.286 & 0.646 & -0.443 \\
\hline Indicated Treatment & 2.073 & 1.697 & 1.221 & -0.009 & 1.374 & -0.006 \\
\hline
\end{tabular}

${ }^{*} p<.05{ }^{* * *} p<.001$. 
Linear Change on Basic Reading From Pre-to Postintervention and Postintervention Through Follow-Up

\begin{tabular}{|c|c|c|c|c|c|c|}
\hline \multirow[b]{2}{*}{ Fixed Effect Variables } & \multicolumn{3}{|c|}{ Preintervention to Postintervention } & \multicolumn{3}{|c|}{ Postintervention Through Follow- $U_{p}$} \\
\hline & Coefficient & Error & T-ratio & Cotficient & Error & T-ratio \\
\hline Universal Intercept & $105.831^{* * *}$ & 5.652 & 18.723 & $98.654^{* * *}$ & 5.429 & 18.172 \\
\hline Age & 0.199 & 0.976 & 0.204 & 0.848 & 0.936 & 0.906 \\
\hline Male & -1.013 & 1.422 & -0.712 & -1.779 & 1.369 & -1.300 \\
\hline Non-White & -2.604 & 1.472 & -1.770 & -2.098 & 1.411 & -1.487 \\
\hline Free lunch & $-3.626^{*}$ & 1.412 & -2.567 & $-2.819^{*}$ & -1.354 & -2.082 \\
\hline Selected Treatment & $-4.133^{* *}$ & 1.556 & -2.655 & -2.898 & 1.503 & -1.928 \\
\hline Indicated Treatment & $-6.428^{*}$ & 2.822 & -2.278 & -4.442 & 2.639 & -1.683 \\
\hline Universal Slope & 5.679 & 4.105 & 1.384 & $6.483^{*}$ & 2.942 & 2.203 \\
\hline Age & -0.301 & 0.710 & -0.424 & -0.722 & 0.509 & -1.416 \\
\hline Male & 0.912 & 1.034 & 0.882 & 0.644 & 0.731 & 0.881 \\
\hline Non-White & -0.818 & 1.071 & -0.763 & -0.222 & 0.767 & -0.289 \\
\hline Free lunch & -0.955 & 1.026 & -0.931 & -0.679 & 0.735 & -0.924 \\
\hline Selected Treatment & -1.059 & 1.126 & -0.940 & -0.681 & 0.798 & -0.853 \\
\hline Indicated Treatment & -2.506 & 2.101 & -1.193 & -1.031 & 1.552 & -0.665 \\
\hline
\end{tabular}

${ }^{*} p<.05 .{ }^{* *} p<.01 .{ }^{* * * *} p<.001$.

suggesting an estimated change of approximately 6 points. Using the postintervention estimate and the change from preintervention would suggest that these students changed from a score of 121 to 115 .

In addition, the random effects were significant for the estimation of the postintervention score $(p<.001)$ but nor the slope $(p>.05)$, indicating a significant amount of variability remains in the estimation of the students' postintervention score after the covariates (i.e., age, male, nonWhite, and free lunch) and treatment groups were modeled, but not in the slope from pre- to postintervention.

Postintervention Through Follow-up. The results of linear growth analysis of the same model but partitioned from postintervention through two follow-up data points is also shown in Table 3. The Universal group ended with a standard score of 102 , which was statistically different from zero (Coefficient $=102.1, S E=4.3, p<.001$ ) The Selected intervention group ended treatment with a significantly higher problem behavior standard score (Coefficient $=10.4, S E=1.4, p<$ $.0001)$ as did the Indicated intervention group (Coefficient $=15.6, S E=2.2, p<.0001$ ), suggesting an estimated standard score difference of 112 and 116 for the Selected and Indicated incervention groups compared to 102 for the Universal group. The covariates did not significantly correlate with the end of treatment standard score.

The slope from postintervention through two data points of follow-up showed only one statistically significant result. The Selected group showed a significant change (Coefficient $=-2.4$, $S E=0.96, p<.05$ ), suggesting that these students maintained the gains they made after intervention as the negative slope coefficient was subtracted from the Universal group slope coefficient (2.509-2.437) and effectively negated the change from postintervention through follow-up. The Indicated intervention group showed a similar magnitude of change (Coefficient $=-2.07$ ), although the amount of variability within this group resulted in a statistically nonsignificant change ( $S E$ $=2.04, p=.31$ ).

The random effects model of the postintervention through follow-up model resulted in statistical significance for the estimates of postintervention $(p<.0001)$ and slope $(p<.001)$, indicating a significant amount of variability remains in the estimation of the students' postintervention score and change from postintervention to 
Linear Growth Curves for the Universal, Selected, and Indicated Groups on Standard Scores of the Problem Behavior Scale

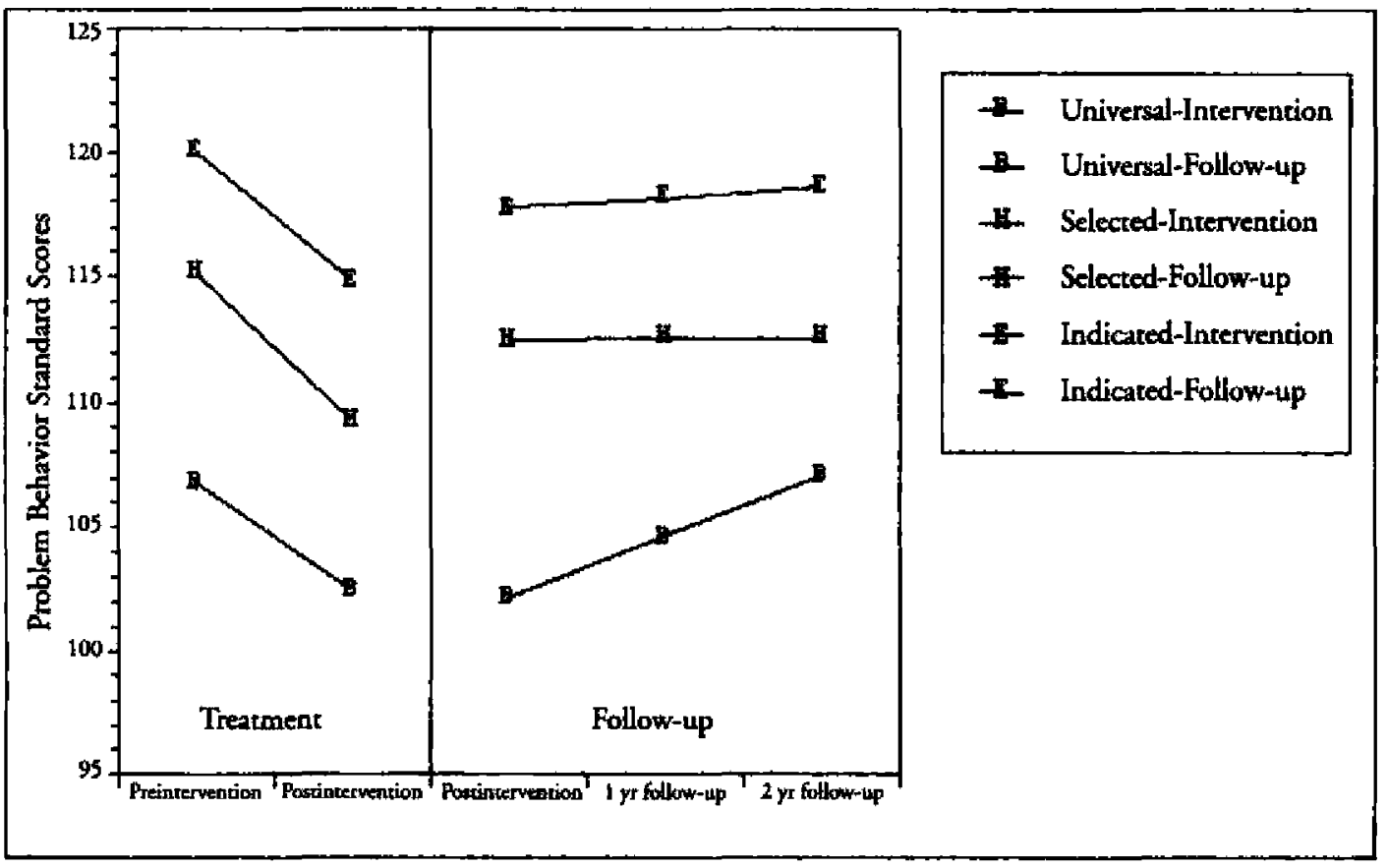

follow-up after the covariates (i.e., age, male, non-White, and free lunch) and treatment groups were modeled.

Figure 1 shows the relative change on the SSRS (Gresham \& Elliot, 1990) Problem Behavior scale based on the two linear growth analyses (preintervention to postintervention and postintervention through follow-up).

\section{EFFECTS ON SOCIAL SKILLS}

Pre- to Postinteruention. The results of the linear growth analyses for the pre- and postintervention as well as the postintervention and follow-up for the SSRS Social Skills scale are presented in Table 4. For the pre- to postintervention, the Universal group ended with a standard score of 97 , which was statistically different from zero (Coefficient $=97.4, S E=4.8$, $p<.001$ ). None of the covariates contributed to the prediction. The Selected intervention group ended treatment statistically lower than the students receiving the Universal group (Coefficient $=-5.4, S E=1.34, p<.001)$ with an estimated standard score of 92 . The Indicated intervention group ended treatment statistically lower than the Universal group (Coefficient $=-8.6, S E=$ $2.4, p<.001)$ with an estimated standard score of about 89 .

The slope from pre- to postintervention showed that the Selected intervention group showed a significant change in social skills (Coefficient $=6.3, S E=1.4, p<.0001$ ). This suggests that these students increased in social skills from about a standard score of 86 to 92 postintervention. The Indicared intervention group also showed a significant change in social skills (Coefficient $=7.4, S E=2.8, p<.01$ ), suggesting an esrimated standard score change from 82 to 89 .

In addition, the random effects were signifcant for the estimation of the postintervention score $(\phi<.001)$ but not the slope $(p>.05)$ indicating a significant amount of variability remains in the estimation of the students' postintervention score after the covariates (i.e., age, male, nonWhite, and free lunch) and treatment groups were modeled, but not in the slope from pre- to postintervention. 
Postintervention Through Follow-Up. The results of linear growth analysis of the same model but partitioned from postintervention through two follow-up data points is shown in Table 4. The Universal group ended with a standard score of 97, which was statistically different from zero (Coefficient $=97.3, \mathrm{SE}=4.9, p<.001$ ) . The Selected (Coefficient $=-8.6, S E=1.4, p<.0001$ ) and Indicated (Coefficient $=-11.7, S E=2.4, p<$ .0001 ) intervention groups ended treatment with a significantly lower social skills standard score, suggesting an estimated standard score difference of 89 and 85 for the Selected and Indicated intervention groups compared to 97 for the Universal group. The covariates did not significantly correlate with the end of treatment standard score.

The slope from postintervention through two data points of follow-up showed only one statistically significant result. The Selected intervention group showed a significant change (Coefficient $=-2.2, S E=1.0, p<.05$ ), suggesting that these students maintained the gains they made after intervention and effectively negated the negative change in comparison to the Universal group. The Indicated intervention group showed a similar magnitude of change (Coefficient $=1.8$ ), although the amount of variability within this group resulted in a statistically nonsignificant change ( $S E=2.5$ ).

The random effects model of the postintervention through follow-up model resulted in statistical significance for the estimates of postintervention $(p<.0001)$ and slope $(p<.001)$, indicating a significant amount of variability remains in the estimation of the students' postintervention score and change from postintervention to follow-up after the covariates (i.e,, age, male, non-White, and free lunch) and treatment groups were modeled. Figure 2 shows the relative change on the SSRS (Gresham \& Elliot, 1990) Social Skills scale based on the two linear growch analyses (preintervention to postintervention and postintervention through follow-up).

\section{EFFECTS OF ACADEMIC COMPETENCE}

Pre- to Postintervention. The results of the linear growth analyses for the pre- and postintervention as well as the postintervention and follow-up for the SSRS Academic Competence scale are pre- sented in Table 5. For the pre- to postintervention, the Universal group ended with a standard score of 92, which was statistically different from zero (Coefficient $=92, S E=4.9, p<.001$ ). The covariate free lunch significantly negatively contributed to the postintervention standard score prediction (Coefficient $=-5.5, S E=1.2, p<$ $.0001)$. The Selected intervention group ended treatment statistically lower than the Universal group (Coefficient $=-2.9, S E=1.2, p<.05$ ).

The slope from pre- to postintervention evidenced no statistically significant change in status, indicating no treatment effects were realized by any of the groups or covariates from pre- to postintervention.

There was a statistically significant random effect for the estimation of the postintervention score $(p<.001)$ but not the slope $(p>.05)$ indicating a significant amount of variability remains in the estimation of the students' postintervention score after the covariates (i.e., age, male, nonWhite, and free lunch) and treatment groups were modeled, but not in the slope from pre- to postintervention.

Postintervention Through Follow- $U_{p}$. The results of linear growth analysis of the same model of the postintervention through follow-up showed the Universal group was statistically significant from zero (Coefficient $=90.9, S E=4.8, p<$ $.0001)$. In addition, free lunch status also predicted lower academic competence standard scores (Coefficient $=-6.7, S E=1.2, p<.0001$ ). The Selecred intervention group also showed a significantly lower standard score (Coefficient = $-2.8, \mathrm{SE}=1.3, \mathrm{p}<.05)$. The Indicated intervention group showed a lower but nonsignificant change because of relatively large error variance (Coefficient $=-3.9, S E=2.4, p=.09$ ).

The slope from postintervention through two data points of follow-up showed only one statistically significant result. The free lunch status variable predicted a significant increase in academic competence (Coefficient $=1.5, S E=0.6$, $p<.05$ ). These results suggest no treatment effect from the selected or indicted interventions on academic competence.

The random effects model of the postintervention through follow-up model resulted in statistical significance for the estimates at postintervention $(\phi<.0001)$ and slope $(p<.001)$, 
FIGURE 2

Linear Growth Curves for the Universal Selected, and Indicated Groups on Standard Scores of the Social Skills Scale

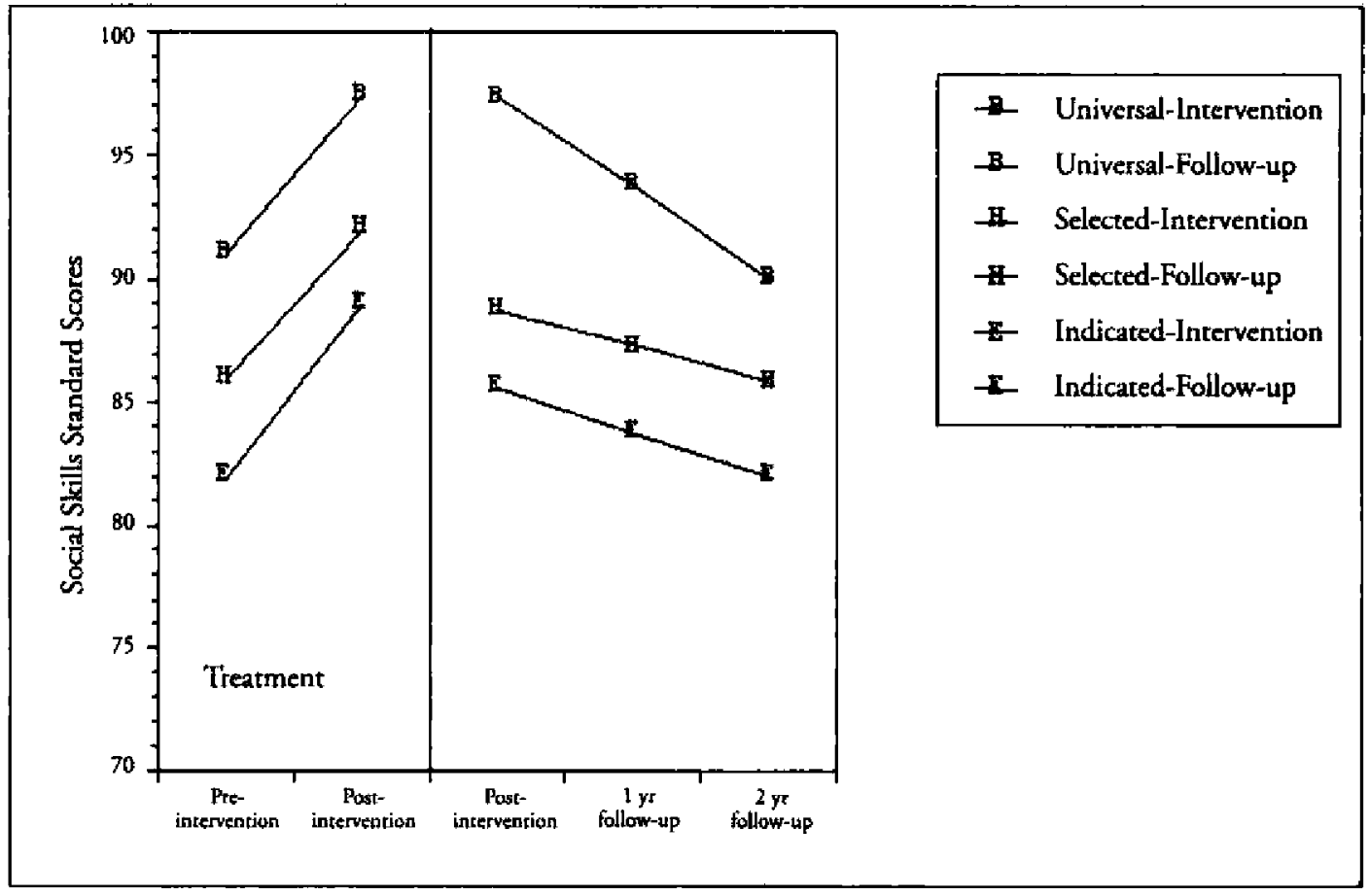

indicating a significant amount of variability remains in the estimation of the students' postintervention score and change from postintervention to follow-up after the covariates (i.e., age, male, non-White, and free lunch) and treatment groups were modeled.

\section{EFFECTS OF BASIC READING}

Pre- to Postintervention. The results of the linear growth analyses for the pre- and postintervention as well as the postintervention through follow-up for the Woodcock-Johnson Basic Reading cluster are presented in Table 6 . For the pre- to postintervention, the Universal group ended with a standard score of 105 , which was statistically different from zero (Coefficient $=105, S E=5.5$, $p<.001)$. The covariate free lunch significantly negatively contributed to the postintervention standard score prediction (Coefficient $=-3.6, S E=$ $1.4, p<.05)$. The Selected and Indicated intervention groups ended treatment statistically lower than the Universal group (Coefficient $=-4.1$,
$S E=1.4, p<.05 ;$ Coefficient $=-6.4, S E=3.0, p$ $<.05$, respectively).

The slope from pre- to postintervention evidenced no statistically significarit change in status, indicating no creatment effects were realized by any of the groups or covariares from pre- to postintervention.

There was a statistically significant random effect for the estimation of the postinrervention score $(p<.001)$ and the slope $(p<.05)$ indicating a significant amount of variability remains in the estimation of the students' postintervention score and change from preintervention to postintervention after the covariates (i.e., age, male, nonWhite, and free lunch) and treatment groups were modeled.

Postintervention Through Follow- $U p$. The results of lineat growth analysis of the postintervention through follow-up showed the Universal group was statistically significant from zero (Coefficient $=98.7, S E=5.6, p<.0001$ ). Free lunch status also predicted a lower standard score (Coefficient $=-2.8, S E=1.4, p<.05$ ). The Selected intervention group also showed a significantly lower 
standard score (Coefficient $=-2.9, S E=1.3, p<$ $.05)$. The Indicated intervention group showed a nonsignificant lower standard score but with a lange error term it did not reach significance (Coefficient $=-4.4, S E=3.0, p=.14$ ).

The slope from postintervention through two data points of follow-up showed only one statistically significant result. The Universal group produced a statistically significant change across the postintervention to follow-up (Coefficient = $6.5, S E=2.7, p<.05)$.

The random effects model of the postintervention through follow-up resulted in statistical significance for the estimates at postintervention $(p<.0001)$ and slope $(p<.001)$, indicating a significant amount of variability remains in the estimation of the students' postintervention score and change from postintervention to follow-up after the covariates (i.e., age, male, non-White, and free lunch) and treatment groups were modeled.

\section{DISCUSSION}

There are calls for schools to use three-tier behavior models to systematically organize interventions to improve the outcomes of children with or at risk of EBD (Gresham, 2004; Horner et al., 2005; Sugai, 2007). Within three-tier behavior models, universal interventions are expected to prevent the onset of problem behavior in a majority of children altogether and to sustain improvements in child outcomes by the selected and indicated interventions. (Mrazek \& Haggerty, 1994). This study assessed the expected child outcomes of a three-tier behavior model based on a behavioral health field framework.

The results generally confirmed our primary hypothesis that the Universal intervention may prevent the onset of behavior problems among a group of low-risk children. The problem behavior and social skills of children in the low-risk Universal group did not appear to change significantly across the study period. The results also generally confirmed our hypothesis that the immediate gains of children who received the Selected (i.e., children at risk of EBD) and Indicated (i.e., children with EBD) interventions would be sustained by the Universal intervention over time. The children who received the Selected intervention showed gains in social skills and reductions in problem behavior that were sustained over time. Further, the gains in social skills and reduction in problem behavior for the children who received the Indicated intervention were not statistically significant because of variability. This variability was, at least in part, a function of overall low and varied treatment fidelity across participants. In addition, these results must be considered in light of the fact that the lunch status of children influenced the results. This finding is consistent with research that indicates that socioeconomic status (SES) has an influence in the social and behavioral development of children (Brooks-Gunn \& Duncan, 1997). Our finding suggests that the SES level of children has an influence on the child outcomes produced by threerier behavior models.

Related to these findings, the results suggest that research-based (i.e., positive outcomes achieved in efficacy studies) Universal, Selected, and Indicated interventions validated in isolated studies appear to produce similar positive outcomes when they are integrated with one another within a three-tier behavior model. The findings of this study generally replicated previous efficacy studies conducted on BASE (Ne)son, 1996; Nelson et al., 2002); First Step to Success (e.g., Golly, Stiller, \& Walker, 1998; Walker, Golly, McLane, \& Kimmich, 2005; Walker et al., 1998); and MST (e.g., Borduin, Henggeler, Blaske, \& Stein, 1990; Borduin, Mann, et al., 1995; Henggeler et al., 1991; Henggeler, Melton, \& Smith, 1992, Henggeler, Pickrel, \& Borduin, 1999; Henggeler et al., 1986).

The results did not confirm our secondary hyporhesis of the extent to which the three-tier behavior model would have a positive effect on the academic performance of children. Although children who received the Selected and Indicated interventions showed improvements in teacher ratings of their social skills and problem behavior, this was not the case with academic comperence. Teacher ratings of their academic competence did not change across the study period. Further, children who received the Selected and Indicated inrerventions showed reductions in their word reading skilis over time relative to children in the low-risk Universal group. Children in the Universal group showed improvements across the study 
period. These findings ate inconsistent with previous studies that have found a small positive relationship between improvements in social behavior and academic performance (e.g., Lassen et al., 2006; Nelson, 1996). This discrepancy may be a function of the fact that preintervention achievement levels of children in the Selected (i.e., children at risk of EBD) and Indicated (i.e., children with EBD) fell within the average range.

\section{LIMITATIONS}

Similar to most educational research, the present study has several limitations. Perhaps the most significant limitation is the location of the sample under study. The three-tier behavior model was studied in seven elementary schools in a mid-size midwestern city. Thus, the organizational structures, instructional practices, and demographic characteristics of the children and staff of the sample of schools limit the statements that can be generalized to schools in other settings. Although age, gender, or ethnic diversity did not influence child outcomes, our finding that the lunch status did affect outcomes suggests that participant samples may influence the outcomes produced by the three-tier models. Thus, the extent to which three-tier behavior models achieve expected child outcomes needs to be replicated with diverse samples of schools.

\section{Teacher ratings of their academic competence did not change across the study period.}

Second, the quasi-experimental cohort longitudinal design does not enable one to draw strong conclusions regarding child outcomes achieved by three-tier behavior models. The main effects of the three intervention levels are confounded by the interaction among them. Randomized field trials are necessary to fully illuminate the effects of three-rier behavior models on child outcomes.

Third, teacher reports of child behavior were the sole source of social behavior data. As such, the data were restricted to adult perceptions of child functioning. Related to this issue, data on the academic performance of children were restricted to teacher reports of academic compe- tence and a norm-referenced measure of word reading skills. It is recommended that in future research, attempts be made to collect direct observation of child behavior and curriculum-based measures of academic achievement.

Fourth, obviously the Universal, Selected, and Indicated interventions that were included in the three-tier model contributed to the findings. It may be that other interventions would have produced different outcomes. Research is not only needed to identify the most efficacious interventions at the universal, selected, and indicated intervention levels, but also what combination of interventions achieve the most desirable outcomes with particular participant samples (e.g., externalizing and internalizing disorders).

Fifth, related to the former issue, selfreported data were used to establish treatment fidelity. Direct observations of actual implementation may have differed from self-reports.

Sixth, the behavioral health approach underlying the three-tier model contributed to the findings. Three-tier behavior models from the behavioral health field use information on the degree of risk to identify the appropriate intensity of intervention for the general, at-risk, and highrisk/disordered popularions. It may be that threetier models based on a public healch response to intervention model in which children move to more intensive levels of treatment when the interventions from the less intensive tier does not produce the desired outcomes may result in different outcomes.

Finally, the extent to which schools can implement three-rier behavior models without the support of external resources is unclear. The Indicated and Selected interventions used in the present study were fully staffed and supported by our research project. Despire this support, there was great variability in the extent to which the Selected and Indicated interventions were implemented among children and families. Future research on three-tier behavior models should focus on implementation of these programs in school environments. We certainly gained an appreciation of the difficulties associated with the implementation of three-tier behavior models. 


\section{IMPLICATIONS}

Despite the limitations, the results of this study indicare that three-tier behavior models may be an effective means to improve the outcomes of children with or at risk of EBD. In contrast to the use of a wide range of isolated interventions, three-tier behavior models provide a systematic approach with which to integrate research based universal, selected, and indicated interventions; or, primary, secondary, and tertiary interventions in the case of a three-tier behavior model based on the public health model. The results of this study also suggest that schools can expect universal, selected, and indicated interventions validated in isolated studies to produce similar positive outcomes when they are integrated with one another within a three-tier behavior model. Thus, initiatives to identify scientifically based interventions aimed at improving student outcomes such as the What Works Clearinghouse (www.whatworks.ed.gov) and Blue Print Programs (http://www.colorado.edu/cspv/index. html) can be used reliably by schools to identify universal, selected, and indicated interventions that can be integrated within three-tier behavior models. However, the finding that SES has a negative effect on student outcomes suggests that the effectiveness of interventions will vary based on the socioeconomic status of the community as well as other variables.

\section{FUTURE RESEARCH}

We sense that scholars and schools are optimistic about the potential for three-rier behavior models to improve the outcomes of children with or at risk of EBD. Indeed, three-tier behavior models are one of the most frequently addressed topics at professional conferences and in professional journals. However, we argue much research is needed prior to the wholesale adoption of three-tier behavior models by schools. We recommend that programmatic research be advanced in two fundamental areas. The first line of research focuses on developing and validating the components of three-tier behavior models. Similar to three-tier academic models, the primary components include screening and progress monitoring measures and benchmarking approaches as well as standards; universal, selected, and indicated interventions; professional development practices; and sustainability of programs over time. One obstacle to advancing the use of three-tier behavior models is the limited availability of screening and progress monitoring measures and benchmarking approaches as well as standards. Such measures, approaches, and standards are consistent with three-rier models for academics, where schools use academic screeners (such as Dynamic Indicators of Basic Early Lireracy Skills; htrp:// dibels.uoregon.edu/) to identify children experiencing reading difficulties.

Another obstacle to advancing the use of three-tier behavior models is the relatively limited number of research-based universal, selecred, and indicated interventions available to school-based practirioners seeking to develop and implement three-tier behavior models. The use of population-based randomized control trials is critically important to establishing the efficacy and effectiveness of universal, selected, and indicated intervention programs. Still another obstacle is the limited information available on the professional development required to develop, implement, and sustain three-tier behavior models. Research on the type and level of professional development needed to implement universal, selected, and indicated intervention programs with integrity is essential to guide the development and use of three-tier behavior models by schools.

\section{The use of population-based randomized control trials is critically important to establishing the efficacy and effectiveness of universal, selected, and indicated intervention programs.}

The second programmatic line of research centers on the conditions necessary to support the successful development and implementation of three-tier behavior models. Three-tier behavior (and academic) models consist of a host of components (e.g., screening and progress monitoring, tiers of interventions, professional development) that must be integrated into a unitary system to be effective. It is clear that there are many situational 
and contexrual facrors (e.g., SES level, school climate, administration leadership, mobility rate of faculty and children) that will have an influence on the type and effectiveness of three-tier models. Practitioners need a clear picture of factors that facilitate as well as impede their efforts to develop and implement effective three-tier models. Research is needed to clarify what type of three-tier models produce positive changes in both the social behavior and academic performance of children. Some scholars suggest that schools must implement combined three-tiet behavior and academic models to achieve positive changes in social behavior and academic performance (e.g., Stewart, Benner, Martella, \& Marchand-Martella, 2007). The complexity and strain on school resources of combined three-tier behavior and academic models requires substantial research clarifying whether and/or how such tiered models might be implemented effectively by schools.

\section{REFERENCE:}

Achenbach, T. M. (2001). Mantual for the child behavior checklist4-18 and 2001 profile. Burlington: University of Vermont, Department of Psychiatry.

Al Otaiba, S., \& Fuchs, D. (2002). Characteristics of children who ate unresponsive to early literacy interrention. Remedial and Special Education, 23(5), 300-316.

Al Otaiba, S., \& Fuchs, D. (2006). Who are the young children for whom best practices in reading are ineffective: An experimental and longitudinal study. Journal of Learning Disabilities, 39, 414-431.

Beelman, A., Pfingsten, U., \& Losel, F. (1994). Effects of training social competence in children: A meta-analysis of recent evaluation studies. Journal of Clinical Child Psychology, 23, 260-271.

Borduin, C. M., Henggeler, S. W., Blaske, D. M., \& Stein, T. (1990). Multisystemic treatment of adolescent sexual offenders. International Joumal of Offender Therapy and Comparative Criminology 35, 105-114.

Borduin, C. M., Mann, B. J., Cone, L. T., Henggeler, S. W., Fucci, B. R., Blaske, D. M., et al. (1995). Multisystemic treatment of serious juvenile offenders: Longterm prevention of criminology and violence. Journal of Consulting and Clinical Pyychology, 63, 569-578.

Bracken, B. A, Keith, L. K, \& Walker, K. C. (1994). Assessment of preschool behavior and social-emotional functioning: A teview of thirteen third-party instruments. Assessment in Rehabilitation and Exceptionality, I, 331-346.

Brooks-Gunn, J., \& Duncan G. J. (1997). The effects of poverty on children. Future Child, 7, 55-71.

Busse, R. T., \& Elliott, S. N. (2001, May). Convergent evidence scaling for multiple outcome indicators. Paper presented at the 2001 APA Program Division 16 School Psychology Conference: San Francisco, CA.

Demaray, M. K, \& Ruffalo, S. L. (1995). Social skills assessment: A comparative evaluation of six published rating scakes. School Psychology Review, 24, 648-672.

Department of Healch and Human Services. (2000). Surgeon General's Report on Children and Mental Health. Washington, DC: Centers for Disease Control and Prevention.

Golly, A., Stiller, B., \& Walker, H. M. (1998). First Step to Success: Replication and social validation of an early intervention program. Journal of Emotional and Behavioral Disorders, 6, 243-251.

Gordon, R. (1983). An operational classification of disease prevention. Public Health Reports, 98, 107-109.

Gresham, F. M. (2004). Current status and future directions of school-based behavioral interventions. School Psychology Revieus, 33, 326-343.

Gresham, F. M., \& Elliot, S. N. (1990). Social Skill Rating System. Circle P'ines, MN: American Guidance Service.

Henggeler, \$. W., Borduin, C. M., Melton, G. B., Mann, B. J., Smith, L., Hall, J. A., et al. (1991). Effects of multisystemic therapy on drug use and abuse in serious juvenile offenders: A progress report from two outcome studies. Family Dynamics of Addiction Quartertys l, 40-51.

Henggeler, S. W., Melton, G. B., \& Smith, I. A. (1992). Family preservation using multisystemic therapy: An effective alternative to incarcerating serious juvenile offenders. Journal of Consulting and Clinical Psychology 60, 953-961.

Henggeler, S. W., Pickrel, S. G., \& Borduin, M. J. (1999). Multisystemic treament of substance abusing and dependent delinquents: Outcomes, treatment fidelity, and transportability. Mental Health Services Research, 1, 171-184.

Henggeler, S. W., Rodick, J. D., Borduin, C. M. Hanson, C. L., Watson, S. M., \& Urey, J. R. (1986). Multisystemic treatment of juvenile offenders: Effects on adolescent behavior and family interactions. Developmental Pychology, 22, 132-141. 
Henggeler, S. W., Schoenwald, S. K, Borduin, C. M. Rowland, M. D., \& Cunningham, P. B. (1998). Multisystemic treatment of antisocial behavior in children and adolescents. New York: Guilford.

Hinshaw, S. P. (1992). Exrernalizing behavior problems and academic underachievement in childhood and adolescence: Causal relationships and underlying mechanisms. Psychological Bulletin, 111, 127-155.

Hops, H., \& Walker, H. M. (1988). CLASS: Contingencies for Learning Academic and Social Skills. Seattle, WA: Educational Achievement Systems.

Horner, R. H., Sugai, G., Todd, A. W., \& LewisPalmet, T. (2005). School-wide positive behavioral support: An alternative to discipline in schools. In L. M. Bambara and L. Kern (Eds), Individualized supporss for students with problem behaviors (pp. 359-390). New York: Guilford.

Lassen, S. R., Sreele, M. M., \& Sailor, W. (2006). The relationship of school-wide positive behavior support to academic achievement in an urban middle school. $B_{t y}$ chology in the Schools, 43, 701-712.

Martella, R. C., Nelson, J. R., \& Marchand-Martella, N. E. (2003). Developing school-uide, classroom, and individual intervention and support programs: $A$ social Learning perspective. Boston: Altyn \& Bacon.

Merrell, K. W., \& Gimpel, G. A. (1998). Sacial skills of children and adolescents: Conceptualization, assessment, treatment. Mahwah, NJ: Erlbaum.

Mrazek, P. G., \& Haggerty, R. J. (1994). Reducing risks for mental disorders: Frontiers for preventive intervention research. Washington, DC: Narional Acadenyy Press.

Nelson, J. R. (1996). Designing schools to meet the needs of students who exhibit disruprive behavior. Journal of Emotional and Behavional Disorders, 4, 147-161.

Nelson, J. R., Benner, G. J., \& Gonzalez, J. (2003). Learner characteristics that influence the treatment effectiveness of early literacy incerventions: A metaanalytic review. Learning Disabilities Research and Practice, 18, 255-267.

Nelson, J. R., Benner, G. J., Lane, K., \& Smith, B. (2004). Academic skills of $K-12$ scudents with emotional disturbance. Exceptional Children, 71, 59-74.

Nelson, J. R., \& Carr, B. A. (2000). The Think Time Strategy for schools. Denver, CO: Sopris West.

Nelson, J. R., Martella, R. C., \& Marchand-Martella, N. E. (2002). Maximizing student learning: The effects of a comprehensive school-based program for preventing disruptive behaviors. Journal of Emotional and Bebavioral Disorders, 10, 136-148.
Netson, J. R., Stage, S. A., Epstein, M. H., \& Pierce, C. D. (2005). The effects of a pre-reading intervention on the literacy skills and social behavior of kindergarten children at risk for behavioral disorders and reading difficulties. Exceptional Cbildren. 72, 29-46.

Pearson Assessment. Metropolitan Achievement Test, Eighth Edition (MAT8). (2000). San Antonio, TX: Author.

Pelosi, N. (1996). Reducing risks of mental disorders. American Pychologist, 51(11), 1128-1129.

Raudenbush, S., Bryk, A., Cheong, Y. F., \& Congdon, R. (2004). HLM6: Hierarchical linear and nonlinear modeling. Lincolnwood, IL: Scientific Software Internarional.

Stewart, R. M., Benner, G. J., Martella, R. C., \& Marchand-Martella, N. E. (2007). Three-ties modes of reading and behavior: A reseatch review. Journal of Positive Behavior Interventions, 9, 239-253.

Sugai, G. (2007). Promoting behavioral competence in schools: A commentary on exemplary practices. Psychology in the Schools, 44, 113-118.

Walker, H. M., Golly, A., McLane, J. Z., \& Kimmich, M. (2005). The Oregon First Step to Success replication initiative: Statewide results of an evaluation of the program's impact. Journal of Emotional and Behavioral Disorders, 13, 163-172.

Walker, H. M., Kavanagh, K., Stiller, B., Golly, A., Severson, H. H., \& Feil, E. G. (1998). First Step to Success: An early intervention approach for preventing school antisocial behavior. Journal of Emotional and Behavioral Disorders, 6, 66-81.

Walker, H. M., \& Severson, H. (1990). Systematic Screening for Behavior Disorders (SSBD). Longmont, CA: Sopris West.

Walker, H. M., Severson, H., \& Feil, E. G. (1995). Early Screening Project (ESP). Longmont, CA: Sopris West.

Walker, H. M., Stiller. B., Golly, A., Kavanagh, K., Severson, H., \& Feil, E. (1997). First Step to Success: Helping young childnen overcome antisocial behavior (An early intervencion program for grades $\mathrm{K}-3$ ). Longmont, $\mathrm{CO}$ : Sopris Wesc.

Woodcock, R. W. (1998). Woodcock Reading Mastery Tests-Revised. Circle Pines, MN: American Guidance Service (AGS).

Zins, J. E., Weissberg, R. P., Wang, M. C., \& Walberg, H. J. (2004). Building academic success on social and emotional learning: What does the research say? New York: Teachers College Press. 


\section{ABOUTTHEAUTHORS}

J. RON NeLSON (CEC NE Federation), ProfesSOF; KRISTIN DUPPONG huRLEY (CEC NE Federation), Assistant Research Professor; LORI SYNHORSt (CEC NE Federation), Assistant Research Professor; and michael h. EPSTein (CEC NE Federation), Professor, Center for At-Risk Children's Services, University of Nebraska-Lincoln. scott stage (CEC NC Federation), Associate Professor, Department of Psychology, North Carolina State University, Raleigh. JACqUELYN BUCKLEY (CEC DC Federation), Instructor, Department of Counseling and Human Services, Johns Hopkins University, Baltimore, Maryland.

Address correspondence concerning this article to J. Ron Nelson, Center for At-Risk Children's Services, 202 Barkley Center, Lincoln, NE 68583-0732 (e-mail: rnelson8@unl.edu).

Preparation of this manuscript was supported in part by a grant from the U.S. Department of Education, Office of Special Education Programs (No. H324X010010). Opinions expressed do not necessarily reflect the position of the U.S. Department of Education, and no endorsement should be inferred.

We would like to acknowledge the principals and staff that participated in this study. This project would not have been possible without their sustained support and effort. We would also like to acknowledge Annemieke Golly and Sonja Schoenwald for supporting our implementacion of the First Step to Success and MST intervention programs, respectively.

Manuscripr received December 2007; accepted October 2008.

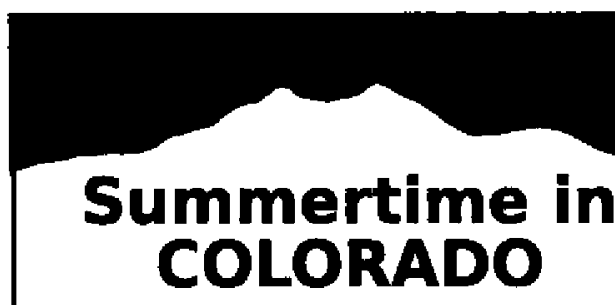

Online and On-Campus

Ph.D. Program in Special Education University of Northem Colorado

Using a variety of distance and on-site methodologies to build a community of practlce including: colloqula, one-week seminars, and discussion groups.

For more information please visit: http://www.unco.edu/cebs/sped/dr_philosophy/ Or Contact: kay.ferrell@unco.edu

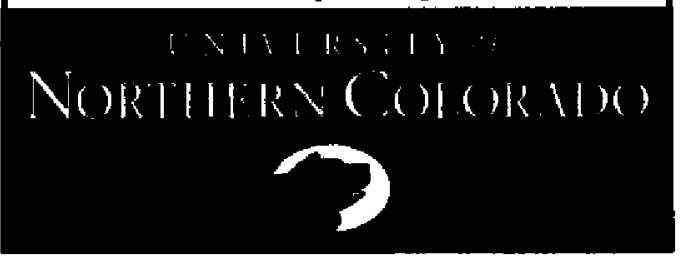

INDEX

$\mathrm{OF}$

\section{ADVERTISERS}

Council for Exceptional Children, cover 2,1, cover 3

Southern Methodist University, 73

University of Northern Colorado, 30 